\title{
Socially Just Design and Engendering Social Change
}

\section{Lynn Dombrowski}

$\mathrm{HCl}$, as a discipline, cares about issues of equity, fairness, and social justice as denoted by the attention of its scholarly works and our evolving dialogue on such topics. For example, within work from $\mathrm{HCl}$ and $\mathrm{HCl}$-related disciplines, such ICT4D, Community Informatics, and Digital Civics, we can find celebratory projects meant to help people eat healthfully, tools that help illtreated workers collectively act to improve their situations, and applications that help those with disabilities to have more equitable access to information (among many others). By social justice within design, I refer to how designers attend to the ways that people experience oppression and marginalization, including how burdens, obligations, power, benefits, and privileges have been unevenly distributed within society. When related to $\mathrm{HCl}$, these concerns are often inclusive of how technology is designed, developed, and used; and how public policy impacts information and communication practices. Often this means that concerns of social justice focus on how oppression, such as racism, sexism, ableism, ageism, classism, and so on, impact people's experiences with technology, information, and design. Taking on a social justice perspective changes how designers engage in design situations, including who they partner with, methods of determining agreeable outcomes, and how designers might interrogate and ask questions of their design situations at hand [see Dombrowski et al., 2016 for more information]. For example, within the space of food insecurity, instead of limiting their design interrogations to current situations by asking "How might I help people who are food insecure to have enough to eat?", designers may additionally inquire about what social inequalities related to food access exist to understand why a person may not have enough to eat in the first place!

Working towards socially just design is not a straight path nor a clear process; instead, it is a constant struggle as the ideals of social justice continually shift to become more inclusive of different concerns. This work is often a road fraught with good faith efforts, allies acting poorly, people struggling to get by, moving targets, evolving tactics, and many design failures. In the Design Justice Lab at Indiana University - Purdue University - Indianapolis (IUPUI), we approach designing for social justice as a multi-pronged effort because we believe that diverse avenues of design, scholarship, and resistance are necessary to work towards the goals of social justice. However, picking up a multipronged effort often requires contending with conflicts that will arise while interrogating multiple, and sometimes competing perspectives. Given that, I wanted to talk briefly about the conversations my students and I have about these topics while designing for social justice amongst a variety of topics including equity issues related to food, worker's rights, immigration, human rights, policing, and so on. Specifically, I want to focus on the different ways we discuss how scholars might conceive of the relationship between design, social justice, and social change.

There are many ways to support social change efforts.

Often, thoughts about social justice and social change go hand in hand as we identify an injustice but may struggle to comprehend what we can do about it. A primary concern for my 
lab is understanding and assessing alternative pathways for social change within the resource constrained and socially marginalized communities with whom we work. While there may be an allure of attending to the most idealized versions of emancipation and empowerment, as designers, we cannot ignore the very real needs that people face today, nor ignore the effects of long-standing trauma within marginalized communities. Relatedly, within the domain of food justice, which focuses on food-related social justice concerns that pervade food systems from production to consumption and includes issues such as hunger, long-standing pesticide exposure, and farm laborer concerns, there are different debates about what kinds of change might be most useful. Some perspectives state that we ought to help people with their immediate health and safety concerns and immediate needs such as ensuring people eat today. Whereas other scholarship focuses on fostering systemic social change (e.g., food deserts, lack of equity in transportation, jobs, and education) that helps change the food system so that future generations will be free of food insecurity. For social change efforts to be workable and useful, we need to both support their urgent and immediate needs and try to foster longerterm social change. Ideally, focusing on both the changes we can make today, as well as longer term social change so that that our efforts are not needed in the future, appears to be necessary, otherwise those needs will continue to persist. In my lab, we have discussions focused on trying to balance current needs with trying to work towards new futures and the design projects range from fostering better, more timely food donations to persuasive, interactive data visualizations and applications that help nonprofits motivate donors, politicians, and communities.

You might also be wondering given that social change is very ambitious endeavor, why do we think that interaction design can help facilitate real change? We struggle with this question, too. Intellectually, we believe that better access to specific forms of social, collaborative information may help people collectively act to contend with wicked social problems. Thus, in my lab, we try to better understand what sociotechnical forms that data and design might take to foster social change. For example, how do we design an application that helps identify which soup kitchen might be able to use hundreds of pounds of excess hot and prepared food, how do we design a mobile application that helps an undocumented worker track their work hours to help them get paid for work completed, how do we help governmental aid recipients understand if they are getting the right benefits. However, pragmatically, we know that there are many facets of wicked social problems where traditional design approaches may not be the best avenue. Instead we might need to focus on efforts such as education, community building, active citizen engagement, voting, or donations as more impactful alternatives. Thus, as part of our approach, we try to assess and understand when and under what condition is taking a computation and interaction design approach appropriate and when it is not.

\section{Engaging community partners in resistance.}

We know that partnering with communities is useful in the design process because it helps designers better understand their partners' practices, desires, and goals. By working with communities, it fosters necessary mutual trust and helps designers check their assumptions about people and a design space. Partnering with communities may additionally yield other benefits as they can also help designers better understand what possible preferable futures 
may exist and different ways to collectively think about how to work towards those futures. Across our field work and partnerships, we see people who are actively trying to resist oppressive practices, policies, data, and people. We see urban farmers trying to understand how data, social media, and marketing might help them reclaim agriculture from "big agri" business; and community social workers trying developing alternatives to state-controlled websites to help their people better understand their legally entitled benefits. In each of these examples, we see people creating and enacting narratives about how things could be different in ways that oppose or resist destructive narratives and acts that hinder communities.

Fostering resistance is an approach to creating the possibility for positively changing the relationship between the oppressed and the oppressor; however, because the people often in most need of social justice are typically the most vulnerable and most resourced constrained, my lab has been having conversations about the merits of different forms of resistance which might engender the possibility for change to occur. Many types of direct resistance, such as active protests and civil disobedience, exist. There are also more subversive, less obvious practices like "peasant resistance" [Scott, 1995], where people do not directly contest a powerful oppressor, but instead engage in noncompliance practices. Design has great potential to help in these scenarios as designers attend to and build towards their partners preferred form of resistance.

Conflict, while uncomfortable, is necessary in a social justice-oriented design process. When engaging in a thorny issue with various stakeholders, a designer has to work across and between multiple sets of institutional and organizational policies, expectations, and relations. Conflict, in various forms, is likely to occur and the presence of conflict in socially just design, while it may seem like an impediment, is actually a healthy sign that a project is tackling topics worth discussion. This is especially true for marginalized people who have, "... interests in asking questions [about power, oppression, and inequality], and dominant groups have interests in not hearing them" [Harding, 1998]. Given marginalized groups frequently lack protection during disagreements, we often try to understand how to scaffold conflicts in a way that best protects these groups. Given all of that, a designer is likely to experience multiple places where conflict is possible as they are managing those different expectations from their community partners and institutions. In my lab, we see these conflicts come up in several, pragmatic ways. For example, we will discuss the boundaries, opportunities, and tensions of being a good ally for a social justice cause when you do not necessarily participate in the struggle directly because you are not a part of the marginalized class. Another source of conflict is managing both institutional responsibilities and community goals (i.e., what's useful for tenure may not be what the community would find useful). Thus, conflict is to be expected in the design process, but will be difficult given the variety of places where dissonance can occur (e.g., responsibilities as a good partner to a community organization versus the institutional obligations as an academic).

Conflicts also happen when people might share the same goal, but may vehemently disagree on how to reach that goal. Hunger-focused nonprofits all have a shared goal of wanting to serve their community. However, these organizations have fundamental disagreements about how to 
demonstrate and defend that they actual help their communities become more food secure. Typically, many such nonprofits tell their funders and donors about how much food they have delivered to demonstrate impact. However, some of these organizations articulated that pounds of delivered food was not a good proxy for their actual impact on the local community. Thus, they wanted to demonstrate impact by showing how their programs, rather than just give food, actual help make people less food insecure. This definitional work matters for the kinds of data they collect and the programs they develop as they do the work of developing more resilient food communities. Thus, this conflict was an opportunity to rethink how they were understanding and evaluating their own impact.

\section{Being an accomplice requires pragmatics and self-emotional care.}

Lastly, an under discussed facet of working towards social change is the affective or emotional labor this work often requires. For scholars who take up this work, it tends to be both deeply personal and at times emotionally difficult. Within social justice work, there is a distinction often made between being an ally and being an accomplice. Typically, an ally might be able to better advocate for an issue to external stakeholders and those who are not yet enrolled into the problem; whereas an accomplice directly works with the affected community and actively takes on risks for the benefit of the group. There are several tensions regarding the politics of being an ally versus an accomplice.

First, from my personal experience, scholars and designers who take up this style of work tend to do so because they feel a deep personal connection with a vulnerable group. Frequently, the people who do this style of work are often themselves a part of a vulnerable group, but also feel in some way that they are privileged because they are scholars or have in some way "made it." Thus, in various aspects of their lives they are simultaneously marked with particular privileges while also contending with feeling marginalized. Secondly, a single person cannot be an accomplice for all social issues that they might care about at all times. To be a good accomplice (and ally) requires resources, time, and energy and thus people must choose which issues to actively tackle. Often people sway between being an accomplice and ally for different issues throughout their social networks.

While I do not have perfect answers for these tensions, in my lab, I advocate that we identify our own limits and that of our work. That we ought to remind ourselves that the social issues we deal with have long legacies and deep roots and while we do not know what effect our small design interventions might have, the work we do is prudent and timely. Lastly, social problems are big problems, we may not be to address all of the underlying causes perpetuating an issue, however, through analysis, we can target specific tangible areas where we might be able to gain productive design traction. In my lab, this often results in partnering with nonprofits and activist groups to help strengthen the work they already do.

\section{Conclusions}

While concerns of equity, fairness, and social justice are long standing, in some ways the interaction design and $\mathrm{HCl}$ professions are still in their infancy as the methods, theories, and 
tools we employ are still being shaped, developed, and evaluated. All of these outlined challenges are productive challenges regarding a socially just design practice, we stand to learn a lot about design as we come to better understand the strengths, weaknesses, and tradeoffs of applying design practices towards wicked social problems.

\section{References.}

Lynn Dombrowski, Ellie Harmon, and Sarah Fox. 2016. Social Justice-Oriented Interaction Design: Outlining Key Design Strategies and Commitments. In Proceedings of the 2016 ACM Conference on Designing Interactive Systems (DIS '16). ACM, New York, NY, USA, 656-671

Sandra Harding. 1998. Is Science Multicultural? Postcolonialisms, Feminisms, and Epistemologies. Bloomington: Indiana University Press.

Scott, James C. Weapons of the weak: Everyday forms of peasant resistance. yale university Press, 2008. 